\title{
Clinical Study \\ Effect of Rosiglitazone and Insulin Combination Therapy on Inflammation Parameters and Adipocytokine Levels in Patients with Type 1 DM
}

\author{
Metin Guclu, ${ }^{1,2}$ Ozen Oz Gul, ${ }^{2}$ Soner Cander, ${ }^{1,2}$ Oguzkaan Unal, ${ }^{2,3}$ \\ Guven Ozkaya, ${ }^{4}$ Emre Sarandol, ${ }^{5}$ and Canan Ersoy ${ }^{2}$ \\ ${ }^{1}$ Division of Endocrinology, Sevket Yllmaz Research and Education Hospital, 16310 Bursa, Turkey \\ ${ }^{2}$ Department of Endocrinology and Metabolism, School of Medicine, Uludă̆ University, 16210 Bursa, Turkey \\ ${ }^{3}$ Acibadem Private Hospital, 16210 Bursa, Turkey \\ ${ }^{4}$ Department of Biostatistics, School of Medicine, Uludă̆ University, 16210 Bursa, Turkey \\ ${ }^{5}$ Department of Biochemistry, School of Medicine, Uludă̆ University, 16210 Bursa, Turkey
}

Correspondence should be addressed to Metin Guclu; dr.metinguclu@gmail.com

Received 18 January 2015; Revised 10 March 2015; Accepted 17 March 2015

Academic Editor: Joseph Fomusi Ndisang

Copyright (C) 2015 Metin Guclu et al. This is an open access article distributed under the Creative Commons Attribution License, which permits unrestricted use, distribution, and reproduction in any medium, provided the original work is properly cited.

\begin{abstract}
Aim. To investigate the efficacy of combined therapy of insulin and rosiglitazone on metabolic and inflammatory parameters, insulin sensitivity, and adipocytokine levels in patients with type 1 diabetes mellitus (type 1 DM). Material and Methods. A total of 61 adults with type $1 \mathrm{DM}$ were randomly and prospectively assigned in open-label fashion to take insulin and rosiglitazone $4 \mathrm{mg} / \mathrm{day}(n=30)$ or insulin alone $(n=31)$ for a period of 18 weeks while undergoing insulin therapy without acute metabolic complications. Results. Combination therapy did not significantly improve metabolic and inflammatory parameters, insulin sensitivity, and adiponectin levels. While leptin and resistin levels decreased in both groups (group 1: resistin $6.96 \pm 3.06$ to $4.99 \pm 2.64, P=0.006$; leptin 25.8 \pm 17.6 to $20.1 \pm 12.55, P=0.006$; group 2 : resistin $7.16 \pm 2.30$ to $5.57 \pm 2.48, P=0.031$; leptin $16.72 \pm 16.1$ to $14.0 \pm 13.4, P=0.007$ ) $\mathrm{Hgb}$ and fibrinogen levels decreased only in group 1 ( $\mathrm{Hgb} 13.72 \pm 1.98$ to $13.16 \pm 1.98, P=0.015$, and fibrinogen $4.00 \pm 1.08$ to 3.46 $\pm 0.90, P=0.002)$. Patients in both groups showed weight gain and the incidence of hypoglycemia was not lower. Discussion. The diverse favorable effects of TZDs were not fully experienced in patients with type $1 \mathrm{DM}$. These results are suggesting that insulin sensitizing and anti-inflammatory characteristics of TZDs were likely to be more pronounced in patients who were not totally devoid of endogenous insulin secretion.
\end{abstract}

\section{Introduction}

There has been a progressive increase in the incidence of type $1 \mathrm{DM}$, and several advances in its treatment have been achieved. As a result, an increasing number of patients, who are older and have longer disease durations, are more severely affected by chronic complications [1-3]. Chronic subclinical inflammation, impaired fibrinolytic system activity, and elevated procoagulant factor levels form the basis of atherosclerotic diseases. Consequently, DM has been regarded as a major risk factor for cardiovascular diseases $[4,5]$. Insulin resistance is characterized by limited stimulation of glucose metabolism in muscle and the liver and has been described in patients with poorly controlled type $1 \mathrm{DM}$ [6-8].

Fatty tissue releases a number of adipocytokines associated with neuroendocrine and immune functions. Cytokines such as leptin, resistin, and adiponectin released from these tissues critically impact nutritional status, body fat distribution, metabolic parameters, inflammatory status, atherosclerotic alterations, and insulin resistance [9]. The levels of adiponectin, which is regarded as an antidiabetic, antiinflammatory, and antiatherogenic cytokine, are reported to be depressed in patients with type 2 DM $[10,11]$. However, in some studies, increased adiponectin levels have been 
reported in patients with type $1 \mathrm{DM}$ [12]. Resistin, on the other hand, impairs cellular glucose intake, because it is stimulated by insulin; as a result, hepatic glucose production is increased, leading to impaired glucose tolerance and eventual development of insulin resistance. Owing to its augmenting effect on the production of adhesion molecules, resistin is considered to be having proinflammatory effects in the vascular endothelium $[13,14]$. Leptin has been shown to have important effects on both body energy balance and fat distribution $[15,16]$.

Glucose uptake rates by peripheral tissues, which can be stimulated by insulin in skeletal muscles, decrease over time in patients with type $1 \mathrm{DM}$ and poor glycemic control. These patients have significant hepatic insulin resistance, and the effects of insulin are impaired because of plasma free fatty acids (FFAs) [17-19]. Despite recent advances in the management of DM, it has been suggested that cardiovascular disease-related mortality rates increase as more intensive therapies are required to ensure tight blood glucose control. Therefore, combination therapies are required to ensure tight glycemic control, minimize the risk of macrovascular disease, and reduce other cardiovascular risk factors [20].

Thiazolidinediones (TZDs) act by binding to "nuclear peroxisome proliferator activated receptor-gamma" (PPAR$\gamma$ ), which is chiefly expressed in fatty tissue, and mediate their effects by activating the transcription of the genes that influence adipocyte differentiation as well as glucose and lipid metabolism [21-23]. TZDs decrease the triglyceride concentration in $\beta$-cells, leading to improved $\beta$-cell function. TZDs, apart from their direct effect on fatty tissue, might influence the release of adipocyte-derived signal factors that determine the insulin sensitivity of muscles, such as FFAs, adiponectin, leptin, and tumor necrosis factor-alpha (TNF$\alpha$ ). In addition to their favorable effects on glycemic control, TZDs directly influence vessel walls, decrease vasoconstriction, and inhibit inflammation. Therefore, they inhibit insulin resistance and slow down the atherosclerotic process [24-27]. In addition, it has been shown that TZDs could inhibit hyperglycemia-induced reactive oxygen species production from mitochondria (mtROS) by activating the PPAR $-\gamma$ coactivator- 1 alpha (PGC- $1 \alpha$ ) pathway which could contribute to the prevention of diabetic vascular complications [28, 29]. Agonists of PPAR-gamma and PPAR-alpha have been shown to upregulate the heme-oxygenase- (HO-) system which has been shown to increase insulin sensitivity, improve glucose/lipid metabolism, suppress inflammation/oxidative stress, decrease immune response, and modulate cell-growth/differentiation [30]. It has been also shown that there were beneficial effects of the HO-system in the pathogenesis of type 1 diabetes and related cardiometabolic complications [31].

Although, euglycemic-hyperinsulinemic clamp study is accepted standard for measurement of insulin sensitivity in patients with type $1 \mathrm{DM}$, it is not practical for use and is labor-intensive. Estimated glucose disposal rate (eGDR) is a derived measure of insulin resistance and can be calculated using routine clinical measures such as waist circumferences or waist-to-hip ratio, presence of hypertension, and HbAlc levels. As an insulin sensitivity index, it is well correlated with results obtained from clamp studies and it should be emphasized that lower eGDR levels indicate greater insulin resistance [32, 33].

The purpose of the present study was to investigate the efficacy of combined therapy of insulin and the oral antihyperglycemic agent rosiglitazone, a PPAR $-\gamma$ agonist, on blood glucose regulation, total administered daily insulin dose, metabolic parameters, eGDR, FFAs, inflammatory indicators, and adipocytokine levels in patients with type $1 \mathrm{DM}$ and poor glycemic control despite intensive insulin therapy.

\section{Materials and Methods}

The study was conducted between March 2007 and January 2008 at the Clinic of Endocrinology and Metabolism Diseases, following the approval of the Uludağ University Medical School Ethics Committee. After providing written consent, the patients were considered eligible based on the following criteria: age 18-65 years, diagnosis of type $1 \mathrm{DM}$, and a glycosylated hemoglobin ( $\mathrm{HbAlc}$ ) level $>6.5 \%$ despite 40 -unit (U) intensive insulin therapy, on average, for $\geq 6$ months. Exclusion criteria were renal failure (glomerular filtration rate $<75 \mathrm{mg} / \mathrm{min}$ or creatinine $>1.5 \mathrm{mg} / \mathrm{dL}$ ), chronic hepatic disease or aspartate aminotransferase (AST) and alanine aminotransferase (ALT) levels 2.5 times the normal values, current antidiabetic therapy other than insulin therapy, known history of rosiglitazone allergy, stage II-IV heart failure according to the New York Heart Association (NYHA) classification [34], inability of the patient to enforce strict lifestyle changes, medical nutrition therapy or selfmonitoring of blood glucose levels, ongoing or planned pregnancy, and current lactation.

2.1. Study Protocol. This prospective, open-label, randomized trial investigated the effectiveness of $4 \mathrm{mg}$ /day rosiglitazone for 18 weeks in patients undergoing insulin therapy and without acute metabolic complications in combination with strict lifestyle changes and effective medical nutrition therapy. The patients attended a screening visit (Visit 1) two weeks before randomization, and they were classified into two open-label groups, such that clinical and demographical characteristics were similar in the two groups. The patients were evaluated for lifestyle changes, diet and exercise compliance, and insulin requirements. Their therapies were modified, and the randomization visit (Visit 2) occurred two weeks later. The patients in both groups underwent insulin titration at Visit 2 , and the patients in one group had $4 \mathrm{mg}$ /day rosiglitazone added to their ongoing therapy (group 1), while the patients in the other group were monitored from that point with their most recent insulin titration (group 2). To reduce the risk of side effects, $4 \mathrm{mg}$ rosiglitazone was initially administered in group 1. Then, the patients attended a control visit (Visit 3) four weeks after randomization and a final visit (Visit 4) after 16 weeks. During each of the four visits, variables within six different categories were monitored, including a detailed physical examination; self-monitoring of BG levels; glycemic control; therapy alterations and insulin requirements; adverse events; and biochemical, hematological, and inflammatory parameters, including adipocytokine levels. 
2.2. Glycemic Control and Insulin Titration. In order to measure the direct effect of rosiglitazone, administered insulin doses were not changed unless patients developed acute metabolic complications. Recurrent hypoglycemia, presence of symptomatic hyperglycemia, diabetic ketosis (DK), diabetic ketoacidosis (DKA), and nonketotic hyperosmolar syndrome (NKHS) were considered metabolic complications. While patients with DK, DKA, NKHS, or major hypoglycemia were planned to be excluded from the study and hospitalized if necessary, patients with symptomatic hyperglycemia and recurrent minor hypoglycemia underwent insulin titration. Patients with symptoms of polydipsia, polyuria, weight loss, and nocturia were considered to be having symptomatic hyperglycemia if they also had mean BG levels $>276 \mathrm{mg} / \mathrm{dL}$; minor hypoglycemia if they were aware enough of their condition to administer self-therapy, were symptomatic, and had BG levels $<56 \mathrm{mg} / \mathrm{dL}$; or major hypoglycemia if they were unconscious, were unable to treat themselves, and recovered after therapy administered by others at home or at hospital.

2.3. Laboratory Methods. Blood samples were analyzed for fasting plasma glucose (FPG), urea, creatinine (Cr), AST, ALT, total cholesterol (total-C), high-density lipoprotein cholesterol (HDL-C), low-density lipoprotein cholesterol (LDL-C), and triglycerides (TG) using an autoanalyzer (Aeroset System Operations Manual; Abbot Laboratories, Abbott Park, IL, USA). LDL-C levels in patients with TG values $<400 \mathrm{mg} / \mathrm{dL}$ were calculated using the Friedewald formula as follows: $\mathrm{LDL}-\mathrm{C}=$ total-C $-[(\mathrm{TG} / 5)+\mathrm{HDL}-\mathrm{C}]$.

$\mathrm{HbAlc}$ levels were measured using high performance liquid chromatography (HPLC; BIO RAD Diagnostic Group, Hercules, CA, USA). Spot urine albumin excretion was measured by chemiluminescence immunoassay (Immulite 2500 Analyzer; Siemens, CA, USA), and creatinine levels were measured spectrophotometrically (Aeroset System Operations Manual; Abbot Laboratories, Abbott Park, IL, USA); in addition, the albumin/creatinine ratio (ACR) was calculated.

The eGDR was calculated as follows: $21.158+(-0.009 \times$ WC $)+(-3.407 \times \mathrm{HTN})+(-0.51 \times$ HbAlc $)$, where the WC indicates the waist circumferences and HTN indicates blood pressure and is expressed as 0: no, 1: yes. The range of clampmeasured glucose disposal rates in the eGDR validation study was 3.8 to 13.4, with a range of $\sim 9$ to 11 in those with normal insulin resistance [32].

FFA measurements were conducted using Wako NEFAHR [2] (Wako Chemicals, GmbH, Neuss, Germany) and an in vitro enzymatic calorimetric assay method. The measureable range was $0.01-4.00 \mathrm{mEq} / \mathrm{L}$.

White blood cell (WBC), hemoglobin (Hgb), hematocrit (Hct), and platelet (PLT) measurements were conducted using Cell-Dyn 3700 (MAPSS Laser Differential; Abbott Laboratories, Abbott Park, IL, USA).

Blood samples were collected as indicated and placed in Westergren tubes to establish erythrocyte sedimentation rates (ESRs) in a 1-hour period. The results were recorded as ESR in $\mathrm{mm} / \mathrm{h}$.

Fibrinogen was measured using the Coagulation System, Dade Behring BNII (Dade Behring Inc., Marburg, Germany). The measurable range was $<1.8-3.5 \mathrm{mg} / \mathrm{L}$.
The solid phase enzyme linked immunosorbent assay (ELISA) method was used with a High Sensitivity CRP Enzyme Immunoassay (DRG International Inc., Mountainside, NJ, USA) for the measurement of high-sensitivity Creactive protein (hs-CRP). The measurable range was $<0.1-$ $10 \mathrm{mg} / \mathrm{L}$, and intra- and interassay coefficients were $2.5 \%$ and $2.3 \%$, respectively.

The solid phase ELISA method and a DRG Leptin Enzyme Immunoassay Kit (DRG GmbH, Marburg, Germany) were used to measure leptin. The expected results were $3.84 \pm 1.79 \mathrm{ng} / \mathrm{mL}$ for men and $7.36 \pm 3.73 \mathrm{ng} / \mathrm{mL}$ for women. The intra- and interassay coefficients were $5.95 \%$ and $8.66 \%$, respectively.

Resistin was measured using the ELISA method with Human Resistin ELISA (BioVendor, Brno, Czech Republic). The normal range was considered to be $8.1 \pm 4.0 \mathrm{ng} / \mathrm{mL}$. The intra- and interassay coefficients were $2.8 \%$ and $5.1 \%$, respectively.

Adiponectin was measured using the ELISA method with a High Sensitivity Human Adiponectin ELISA kit (BioVendor, Brno, Czech Republic). The normal range was dependent upon BMI and was $9.5 \pm 3.9 \mu \mathrm{g} / \mathrm{mL}$ for men and $13.2 \pm$ $6.1 \mu \mathrm{g} / \mathrm{mL}$ for women. The intra- and interassay coefficients were $4.1 \%$ and $4.0 \%$, respectively.

2.4. Statistical Analysis. According to pilot study, a sample size of 30 patients per group was calculated to give $80 \%$ power to detect a difference of 6 in change from baseline in mean adiponectin between groups at the 5\% 2-sided significance level, assuming 8 as the common SD. Statistical analyses were conducted using SPSS for Windows (Version 22.0; SPSS Inc., Chicago, IL, USA). Continuous variables are expressed as the mean \pm standard deviation or median (minimum-maximum), as appropriate; categorical variables are expressed as frequencies ( $n, \%)$. A one-way ANOVA was used to compare mean values for normally distributed variables when there were more than two independent groups, and the Kruskal-Wallis test was used when the assumptions for parametric tests were not met. The MannWhitney $U$ test was used for nonparametric comparison of two groups. Paired data were analyzed using paired $t$-test and the Wilcoxon signed rank test when data were not normally distributed. For measurement at last visit, percent changes were calculated according to baseline measurement. These percent changes were compared. Pearson's chi-squared was used for comparison of the frequencies. $P<0.05$ was considered statistically significant in all tests.

\section{Results}

The demographic characteristics and baseline glycemic levels are shown in Table 1.

There were no significant differences between the groups in sex, mean age, disease duration, BW, BMI, waist circumferences, waist-to-hip ratios, FPG, HbAlc values, and eGDR in the baseline and mean $P$ value was higher than 0.05 for all parameters mentioned above. eGDR was 8.53 $\pm 2.70 \mathrm{mg} / \mathrm{kg} / \mathrm{min}$ in group 1 and $9.25 \pm 3.18 \mathrm{mg} / \mathrm{kg} / \mathrm{min}$ in group 2. Patients in group 1 had higher FPG and HbAlc and 
TABLE 1: Comparison of the demographic characteristics and baseline glycemic parameters between the groups.

\begin{tabular}{lccc}
\hline Characteristics & $\begin{array}{c}\text { Group 1 } \\
\text { Insulin + Ros } \\
(n=30)\end{array}$ & $\begin{array}{c}\text { Group 2 } \\
\text { Insulin alone } \\
(n=31)\end{array}$ & $P$ \\
\hline Sex (women/men) & $18 / 12$ & $17 / 14$ & 0.570 \\
Age (years) & $27.55 \pm 8.48$ & $27.09 \pm 5.38$ & 0.734 \\
$\begin{array}{l}\text { Diabetes duration } \\
\text { (years) }\end{array}$ & $10 \pm 4.95$ & $9.6 \pm 4.92$ & 0.814 \\
BW (kg) & $66.59 \pm 8.6$ & $63.13 \pm 8.2$ & 0.768 \\
BMI $\left(\mathrm{kg} / \mathrm{m}^{2}\right)$ & $24.17 \pm 2.62$ & $22.97 \pm 2.74$ & 0.606 \\
WC $(\mathrm{cm})$ & $83.80 \pm 8.26$ & $78.71 \pm 9.11$ & 0.135 \\
WHR & $0.85 \pm 0.06$ & $0.80 \pm 0.06$ & 0.773 \\
FPG $(\mathrm{mg} / \mathrm{dL})$ & $249.1 \pm 69.5$ & $223.2 \pm 78.5$ & 0.167 \\
HbAlc $(\%)$ & $9.22 \pm 1.77$ & $8.75 \pm 1.14$ & 0.886 \\
eGDR $(\mathrm{mg} / \mathrm{kg} / \mathrm{min})$ & $8.53 \pm 2.70$ & $9.25 \pm 3.18$ & 0.120 \\
\hline
\end{tabular}

BW: body weight; BMI: body mass index; WC: waist circumference; WHR: waist-to-hip ratio; SBP: systolic blood pressure; DBP: diastolic blood pressure; FPG: fasting plasma glucose; HbAlc: glycosylated hemoglobin; eGDR: estimated glucose disposal rate.

slightly low eGDR, in other words more insulin resistant than group 2.

The comparisons between the final and baseline values for each group are shown in Table 2.

The total number of patients in each group that completed the study was 28 , as two patients in each group were excluded owing to acute metabolic complications and one patient in group 2 was excluded owing to noncompliance with the visit schedule. During the follow-up period, the changes in BW and BMI were statistically significant in both groups ( $P<0.05$ for group 1 and $P<0.01$ for group 2$)$, whereas the changes in WC and waist-to-hip ratio (WHR) were not significant.

Systolic blood pressure (SBP) significantly decreased in group 2; the changes in diastolic blood pressure (DBP) were similar in both groups. Although the final FPG and HbAlc values were lower than the baseline values in both groups, the changes were statistically significant only in group 2 . No statistically significant differences were found in eGDR during the study period in both groups. eGDR was $8.53 \pm$ $2.70 \mathrm{mg} / \mathrm{kg} / \mathrm{min}$ at baseline and $8.36 \pm 2.45 \mathrm{mg} / \mathrm{kg} / \mathrm{min}$ at final visits in group 1. It was $9.25 \pm 3.18 \mathrm{mg} / \mathrm{kg} / \mathrm{min}$ at baseline and $9.22 \pm 3.20$ at final visits in group 2. $P$ value was 0.185 for group 1 and 0.235 for group 2 in terms of eGDR changes between two visits. Urea, Cr, spot urine ACR, AST, and ALT levels did not significantly change in either group. Of the total-C, HDL-C, LDL-C, TG, and FFA levels, only the HDL-C levels in group 2 significantly changed $(P=0.038)$.

While Hgb and HCT values did not change significantly in group 2, a significant decrease in Hgb levels was observed in group 1. Of the ESR, fibrinogen, and hs-CRP levels, only fibrinogen levels significantly decreased in group 1, and the changes in the other parameters were not significant for either group.
Although the resistin and leptin levels decreased significantly and changes were statistically significant in both groups, adiponectin levels increased but the change was not significant. The total daily insulin doses administered during the follow-up period are also shown in Table 2. The changes observed both between and within the groups in total daily insulin doses per kilogram of BW were not significant.

Comparisons between the groups for the final and baseline values of inflammatory markers, adipocytokine, and FFA levels are shown in Table 3.

The differences between the groups in ESR and hsCRP levels were not significant at both baseline and final visits. However, while the difference in fibrinogen levels was significant at the baseline visit, the values at the final visit were not different owing to the decrease in fibrinogen levels in group 1. Also, the differences between the groups in resistin, leptin, and adiponectin levels were not significant at both baseline and final visits.

Diabetes-related complications experienced by the patients over the 18-week follow-up period are shown in Table 4 .

The mean hypoglycemia frequency was calculated by dividing the number of total hypoglycemia episodes for all of the patients over the 18 -week period by the number of patients, and the mean change in BW for the same period was calculated similarly. The number of patients with acute complications or major hypoglycemic events was expressed as the total frequency for the group. Two patients in group 1 experienced major hypoglycemic events, while two patients in group 2 had to be hospitalized due to DKA (Table 4). While 5.35 minor hypoglycemia episodes were experienced per patient over the 18 weeks in group 1, the mean weight gain was $2.58 \pm 3.10 \mathrm{~kg}$ during the same period. The patients in group 2 , on the other hand, experienced 4.61 minor hypoglycemic episodes per patient, and the mean weight gain was 1.47 $\pm 1.53 \mathrm{~kg}$ during the same period. The $P$ value for minor hypoglycemia was 0.437 , and it was 0.142 for weight gain. Therefore, the difference between the groups with respect to either parameter was not statistically significant. Because of the low number of major hypoglycemia events and acute metabolic complications, statistical comparisons were not possible.

\section{Discussion}

The combined therapy approaches used in type 2 diabetes management have also become increasingly common in type 1 diabetes management. Furthermore, studies have demonstrated that insulin resistance is not exclusively observed in patients with type 2 diabetes and that it is also a critical factor for patients with type 1 diabetes because it can be overlooked in patients without adequate BG regulation [32, 35-38]. The primary goals when introducing insulin-sensitizing agents in combined therapy are ensuring good glycemic control, decreasing insulin demand, achieving favorable effects on cardiovascular risk factors, and minimizing alterations in BW. Strowig and Raskin reported improved glycemic control without an increase in insulin demand in 25 overweight adult patients with type 1 diabetes following therapy with 
TABLE 2: Comparison between the baseline and final (week 16) values for each group.

\begin{tabular}{|c|c|c|c|c|c|c|}
\hline \multirow{2}{*}{ Parameters } & \multicolumn{3}{|c|}{$\begin{array}{c}\text { Group } 1 \\
\text { Insulin }+ \text { rosiglitazone }\end{array}$} & \multicolumn{3}{|c|}{$\begin{array}{c}\text { Group } 2 \\
\text { Insulin alone }\end{array}$} \\
\hline & $\begin{array}{l}\text { Baseline } \\
(n=30)\end{array}$ & $\begin{array}{c}\text { Final } \\
(n=28)\end{array}$ & $P$ & $\begin{array}{l}\text { Baseline } \\
(n=31)\end{array}$ & $\begin{array}{c}\text { Final } \\
(n=28)\end{array}$ & $P$ \\
\hline $\mathrm{BW}(\mathrm{kg})$ & $66.59 \pm 8.6$ & $69.96 \pm 9.29$ & 0.003 & $63.13 \pm 8.2$ & $65.18 \pm 8.20$ & 0.001 \\
\hline BMI $\left(\mathrm{kg} / \mathrm{m}^{2}\right)$ & $24.17 \pm 2.62$ & $25.69 \pm 2.57$ & 0.002 & $22.97 \pm 2.74$ & $23.76 \pm 2.73$ & $<0.001$ \\
\hline $\mathrm{WC}(\mathrm{cm})$ & $83.80 \pm 8.26$ & $86.61 \pm 8.53$ & 0.107 & $78.71 \pm 9.11$ & $80.78 \pm 8.09$ & 0.109 \\
\hline WHR & $0.85 \pm 0.06$ & $0.85 \pm 0.05$ & 0.792 & $0.80 \pm 0.06$ & $0.82 \pm 0.06$ & 0.048 \\
\hline $\mathrm{SBP}(\mathrm{mmHg})$ & $114 \pm 13.63$ & $111.6 \pm 13.7$ & 0.604 & $116 \pm 9.37$ & $110.5 \pm 9.62$ & 0.030 \\
\hline DBP (mmHg) & $75.25 \pm 9.24$ & $70.83 \pm 9.11$ & 0.061 & $75.95 \pm 7.51$ & $72.63 \pm 7.70$ & 0.174 \\
\hline $\mathrm{FPG}(\mathrm{mg} / \mathrm{dL})$ & $249.1 \pm 69.5$ & $219.7 \pm 97$ & 0.460 & $223.2 \pm 78.5$ & $178 \pm 91$ & 0.006 \\
\hline HbAlc (\%) & $9.22 \pm 1.77$ & $9.09 \pm 1.40$ & 0.239 & $8.75 \pm 1.14$ & $8.46 \pm 1.19$ & 0.050 \\
\hline eGDR (mg/kg/min) & $8.53 \pm 2.70$ & $8.36 \pm 2.45$ & 0.185 & $9.25 \pm 3.18$ & $9.22 \pm 3.20$ & 0.235 \\
\hline Urea (mg/dL) & $25.50 \pm 7.17$ & $26.66 \pm 6.2$ & 0.032 & $25.52 \pm 6.03$ & $27.84 \pm 4.96$ & 0.042 \\
\hline $\mathrm{Cr}(\mathrm{mg} / \mathrm{dL})$ & $0.83 \pm 0.16$ & $0.82 \pm 0.26$ & 0.935 & $0.86 \pm 0.12$ & $0.90 \pm 0.31$ & 0.602 \\
\hline ALT (IU/L) & $18.25 \pm 11.4$ & $13.55 \pm 4.3$ & 0.033 & $15.85 \pm 9.85$ & $17.52 \pm 13.3$ & 0.912 \\
\hline Total-C (mg/dL) & $172.8 \pm 36.2$ & $169.0 \pm 31.8$ & 0.935 & $177.3 \pm 33.8$ & $170.1 \pm 34.5$ & 0.678 \\
\hline HDL-C (mg/dL) & $45 \pm 5.90$ & $47.80 \pm 9.37$ & 0.285 & $47.00 \pm 9.35$ & $51.47 \pm 10.60$ & 0.038 \\
\hline LDL-C (mg/dL) & $105 \pm 27.12$ & $98.86 \pm 27.89$ & 0.688 & $111.15 \pm 24.17$ & $107.45 \pm 30.1$ & 0.668 \\
\hline $\mathrm{TG}(\mathrm{mg} / \mathrm{dL})$ & $113 \pm 77.91$ & $111.20 \pm 52.41$ & 0.971 & $79.47 \pm 42.95$ & $81.57 \pm 27.14$ & 0.821 \\
\hline FFA (mEq/L) & $0.57 \pm 0.43$ & $0.53 \pm 0.28$ & 0.913 & $0.49 \pm 0.25$ & $0.47 \pm 0.26$ & 0.601 \\
\hline $\mathrm{ACR}(\mathrm{mg} / \mathrm{min})$ & $35.50 \pm 42.91$ & $23.57 \pm 17.65$ & 0.136 & $19.36 \pm 19.00$ & $12.54 \pm 10.72$ & 0.667 \\
\hline $\mathrm{Hgb}(\mathrm{g} / \mathrm{dL})$ & $13.72 \pm 1.98$ & $13.16 \pm 1.98$ & 0.015 & $13.74 \pm 1.64$ & $13.61 \pm 1.04$ & 0.838 \\
\hline HCT (\%) & $40.55 \pm 5.48$ & $39.06 \pm 5.42$ & 0.067 & $40.53 \pm 4.44$ & $40.65 \pm 2.69$ & 0.428 \\
\hline Resistin & $6.96 \pm 3.06$ & $4.99 \pm 2.64$ & 0.006 & $7.16 \pm 2.30$ & $5.57 \pm 2.48$ & 0.031 \\
\hline Leptin & $25.8 \pm 17.6$ & $20.1 \pm 12.55$ & 0.006 & $16.72 \pm 16.1$ & $14.0 \pm 13.4$ & 0.007 \\
\hline Adiponectin & $17.48 \pm 10.71$ & $19.81 \pm 11.21$ & 0.145 & $11.90 \pm 5.23$ & $15.98 \pm 9.47$ & 0.948 \\
\hline Insulin dose (units/day) & $64.45 \pm 16.31$ & $65.88 \pm 15.29$ & NS & $53.33 \pm 13.45$ & $52.78 \pm 11.07$ & NS \\
\hline
\end{tabular}

BW: body weight; BMI: body mass index; WC: waist circumference; WHR: waist-to-hip ratio; SBP: systolic blood pressure; DBP: diastolic blood pressure; FPG: fasting plasma glucose; HbAlc: glycosylated hemoglobin; eGDR: estimated glucose disposal rate; CR: creatinine; AST: aspartate aminotransferase; ALT: alanine aminotransferase; Total-C: total cholesterol; HDL-C: high-density lipoprotein cholesterol; LDL-C: low-density lipoprotein cholesterol; TG: triglycerides; FFA: free fatty acids; ACR: albumin/creatinine ratio; Hgb: hemoglobin; Hct: hematocrit.

TABLE 3: Comparisons between the groups for inflammatory marker, FFA, and serum adipocytokine levels at baseline and at the final visit (week 16).

\begin{tabular}{|c|c|c|c|c|c|c|}
\hline \multirow[b]{2}{*}{ Parameters } & \multicolumn{3}{|c|}{ Randomization visit } & \multicolumn{3}{|c|}{ Final visit } \\
\hline & $\begin{array}{c}\text { Group } 1 \\
\text { Insulin + Ros }\end{array}$ & $\begin{array}{c}\text { Group } 2 \\
\text { Insulin only }\end{array}$ & $P$ & $\begin{array}{c}\text { Group } 1 \\
\text { Insulin + Ros }\end{array}$ & $\begin{array}{c}\text { Group } 2 \\
\text { Insulin only }\end{array}$ & $P$ \\
\hline $\mathrm{ESR}(\mathrm{mm} / \mathrm{h})$ & $11.85 \pm 11.36$ & $10.89 \pm 10.39$ & 0.969 & $14.44 \pm 13.14$ & $11.00 \pm 8.76$ & 0.599 \\
\hline Fibrinogen $(\mathrm{g} / \mathrm{L})$ & $4.00 \pm 1.08$ & $3.46 \pm 0.90$ & 0.047 & $3.46 \pm 0.90$ & $3.11 \pm 0.92$ & 0.271 \\
\hline hs-CRP (mg/L) & $2.32 \pm 2.64$ & $1.41 \pm 1.69$ & 0.361 & $1.76 \pm 1.14$ & $1.76 \pm 2.31$ & 0.443 \\
\hline FFA (mEq/L) & $0.57 \pm 0.43$ & $0.49 \pm 0.25$ & 0.917 & $0.53 \pm 0.28$ & $0.47 \pm 0.26$ & 0.518 \\
\hline Resistin (ng/mL) & $6.96 \pm 3.06$ & $7.16 \pm 2.30$ & 0.489 & $4.99 \pm 2.64$ & $5.57 \pm 2.48$ & 0.650 \\
\hline Leptin (ng/mL) & $25.8 \pm 17.6$ & $16.72 \pm 16.1$ & 0.130 & $20.1 \pm 12.55$ & $14.0 \pm 13.4$ & 0.724 \\
\hline Adiponectin $(\mu \mathrm{g} / \mathrm{mL})$ & $17.48 \pm 10.71$ & $11.90 \pm 5.23$ & 0.760 & $19.81 \pm 11.21$ & $15.98 \pm 9.47$ & 0.091 \\
\hline
\end{tabular}

Ros: rosiglitazone; ESR: erythrocyte sedimentation rate; hs-CRP: high-sensitivity C-reactive protein; FFA: free fatty acids. 
TABLE 4: Complications observed in the groups.

\begin{tabular}{lccc}
\hline Complication & $\begin{array}{c}\text { Group 1 } \\
\text { Insulin + Ros }\end{array}$ & $\begin{array}{c}\text { Group 2 } \\
\text { Insulin }\end{array}$ & $P$ \\
\hline $\begin{array}{l}\text { Minor hypoglycemia events } \\
\text { experienced per patient }\end{array}$ & 5.35 & 4.61 & 0.437 \\
$\begin{array}{l}\text { Major hypoglycemia events } \\
\begin{array}{l}\text { Acute metabolic complication } \\
\text { DK/DKA/NKNAHS }\end{array}\end{array}$ & - & - & NA \\
Mean weight gain $(\mathrm{kg})$ & $2.58 \pm 3.10$ & $1.47 \pm 1.53$ & 0.142 \\
\hline
\end{tabular}

Ros: rosiglitazone; DK: diabetic ketosis; DKA: diabetic ketoacidosis; NKNAHS: nonketotic nonacidotic hyperosmolar syndrome; NA: not available.

$4 \mathrm{mg}$ rosiglitazone twice a day for 8 months [39]. Although patients in both groups in the present study had decreased FPG and HbAlc levels, the changes were not significant. Baseline glucose and HbAlc values were higher in the patients receiving rosiglitazone; however, the differences in the changes between the groups were not significant. In a study conducted by Stone et al. [40], 36 patients with type 1 diabetes whose daily insulin requirement was $>1.1 \mathrm{U} / \mathrm{kg}$ were administered $8 \mathrm{mg} /$ day rosiglitazone. The investigators reported that the change in HbAlc levels was not significant when compared with the placebo group.

For decades, type 1 diabetes has been traditionally known as insulin-dependent, while type 2 has been known as noninsulin-dependent diabetes. However, it is becoming increasingly clear that insulin deficiency and insulin resistance are manifested in both forms of diabetes at different stages. Unlike other studies [39, 40] which investigate the effects of TZDs on insulin resistance and consist of obese or overweight patients with type $1 \mathrm{DM}$, almost all of the patients were lean in present study. eGDR is a validated clinical tool for estimating insulin sensitivity in patients with type $1 \mathrm{DM}$. It was near normal at baseline and did not change significantly during our study period in both groups. This result was important to show effects of rosiglitazone, except insulinsensitizing characteristics. Thus, it can be thought that the effects of rosiglitazone observed in present study were not associated with insulin sensitivity. One of the known major effects of these drugs is on oxidative stress and mitochondrial ROS production. These effects may be key factors during the development of diabetic vascular complications. It has been shown that TZDs could inhibit hyperglycemia-induced mtROS and contribute to the prevention of diabetic vascular complications [41]. Although there were some studies investigating these effects in patients with type $2 \mathrm{DM}$, it is unclear in patients with type $1 \mathrm{DM}$. It is obvious that there is a need to investigate this effect in prospective cohort studies composed of patients with type 1 DM. In addition, agonists of PPARgamma might increase insulin sensitivity via upregulating heme-oxygenase-system. The HO-system and related products have been shown to decrease inflammation and enhance insulin sensitivity. More importantly, in experimental models of type $1 \mathrm{DM}$, upregulating $\mathrm{HO}$-system caused increase in pancreatic beta cell insulin production. Beneficial effects of TZDs on insulin resistance and inflammation resulting from
HO-system have been studied in patients with both type 2 and type $1 \mathrm{DM}[30,31,42]$. These developments may offer new options, either prevention of disease or development of the complications.

We observed significant BW and BMI changes in all patients at the final visit compared with baseline values. However, weight gain did not significantly differ between the baseline and final visits. The most significant side effect of TZDs, particularly when combined with sulfonylurea and insulin, is weight gain. TZDs increase overall fat tissue, and the most affected area is subcutaneous fat tissue. Another major cause of TZD-related weight gain is increased water and salt retention, which leads to increased plasma volume. Consequently, these drugs might lead to complications in patients with heart failure. Edema is caused by depressed renal sodium excretion and free water retention [43-45]. Sotton et al. reported a $10 \%$ increase in left ventricular mass without significant alterations in cardiac structure and function in patients undergoing rosiglitazone therapy. They attributed it mainly to the increase in plasma volume [46]. Although we observed weight gain in our patient groups in this present study, no patient had heart failure. Moreover, peripheral edema or dyspnea was not among the adverse events reported by our patients. This could be attributed to the relatively young mean age in our sample or to the fact that heart failure at baseline was among the exclusion criteria. Furthermore, no patient in this cohort had diabetic nephropathy that could lead to edema, which might have decreased the risk for edema.

The hypoglycemic effects of TZDs include increased insulin sensitivity that is mediated through TG and FFA metabolism and is associated with the agonistic effects of PPAR- $\gamma$. Increased FFA levels lead to insulin resistance and fasting plasma FFA levels in patients with type 2 diabetes administered TZD might decrease by $20-30 \%$. PPAR$\gamma$ activation impairs TG and fatty acid synthesis, leading to decreased very-LDL-C and HDL-C synthesis as well as increased LDL-C and total-C levels $[47,48]$. The patients in the present study with BMI and WC levels in the normal range had baseline TG and HDL-C levels within the desired range, and the LDL-C levels in all patients were close to $100 \mathrm{mg} / \mathrm{dL}$. While slight decreases in total-C, LDL-C, TG, and FFA levels were noted in the patients receiving rosiglitazone at the end of the present study, HDL-C levels had increased slightly. Patients receiving only insulin had similar values to those in the combined therapy group except for slightly higher TG levels, although this was not statistically significant. Comparisons within and between the groups did not show significant differences. We suggest that the strict enforcement of lifestyle changes during the follow-up period might have contributed to these results.

TZDs have been demonstrated to have significant antiinflammatory characteristics in studies conducted on patients with type 2 diabetes. Calkin et al. reported that rosiglitazone reduces diabetes-related atherosclerosis and that this effect is possibly associated with oxidative stress and inflammation, independent of metabolic effects, unrelated to the insulin dose [49]. In particular, the Diabetes Control and Complications Trial, as well as a number of other studies, revealed 
that hs-CRP levels increased in patients undergoing intensive therapy. Furthermore, hs-CRP and increased fibrinogen levels are independent risk factors for coronary heart disease, and a number of studies have reported elevated fibrinogen levels in patients with diabetes $[50,51]$. The ESR levels in the present study were within the normal range at baseline, and they continued to be so until the end of study. While hs-CRP levels decreased with respect to baseline values in the patients receiving rosiglitazone in the present study, they increased slightly in the patients receiving insulin alone. To the best of our knowledge, this is the first study to measure fibrinogen levels in patients with type 1 diabetes after rosiglitazone administration. The levels decreased significantly in these patients, while the patients undergoing therapy with insulin alone showed minimal decreases in fibrinogen levels. Independent of the improvement in BG regulation, levels of hs-CRP and fibrinogen, which are conventional inflammatory markers, decreased significantly following rosiglitazone therapy in the present study.

Plasma leptin levels are positively correlated with female sex, BMI, and age but not with diabetes duration, HbAlc, or total insulin dose per kilogram [52]. Most patients with type 1 diabetes are either underweight or in the normal BW range. Data concerning leptin levels in this group of patients vary, and exogenous insulin therapy leads to elevated leptin levels in patients with type 1 diabetes $[53,54]$. Resistin, which is released from adipose tissue, is directly associated with insulin resistance factors such as WC and WHR. Shalev et al. reported increased serum resistin levels in patients with type 1 diabetes and reported that levels returned to the normal range after pancreas transplant $[55,56]$. The patients in the present study had normal BW, BMI, and WC. The leptin levels were within the normal range at both baseline and final visits. While no significant differences were observed between the groups at the baseline or final visit or in the change between the visits, the within-group changes during the follow-up period were significant, despite the weight gain. Resistin levels were low in both groups, and the change in the patients receiving rosiglitazone was significant, despite weight gain, and was associated with the favorable effects of rosiglitazone.

Adiponectin has been shown to have positive effects on cardiometabolic risk, and adiponectin levels are negatively correlated with insulin resistance and weight gain. Moreover, good glycemic control increases adiponectin levels, whereas poor glycemic control decreases adiponectin levels [57, 58]. In the CACTI trial, Maahs et al. reported negative correlations between adiponectin levels and male sex, central adiposity, SBP, DBP, daily insulin dose, HbAlc, fibrinogen, albumin excretion rate, and TG levels; positive correlations were noted with type 1 diabetes, HDL-C, and homocysteine [59]. In the present study, adiponectin levels increased parallel to glycemic improvement both in patients undergoing combined therapy and in those receiving insulin therapies alone. Thus, the increase was independent of the therapy.

In conclusion, the diverse favorable effects of TZDs previously reported in patients with type 2 diabetes were not fully experienced in patients with type 1 diabetes in the present study. The addition of $4 \mathrm{mg} /$ day rosiglitazone to intensive insulin therapy did not significantly improve glycemic parameter, lipid parameter, FFA, ESR, hs-CRP, leptin, or resistin levels. Only fibrinogen levels were significantly different between the groups. Patients receiving rosiglitazone showed weight gain, a major side effect of TZDs, whereas insulin sensitivity was not significantly different and the incidence of hypoglycemia was not lower. HbAlc, FPG, and total daily insulin doses decreased significantly after combination therapy with TZD and insulin in patients with type 2 diabetes mellitus, suggesting that the insulin-sensitizing characteristics of TZDs are likely more pronounced in patients who are not totally devoid of endogenous insulin secretion.

We acknowledge the limitations of the current study including single centre experience and small sample size. Patients treated in our series did not appear to have driven any meaningful benefit from combination therapy. Due to small number of patients included in study, prospective clinical trials are however required to define optimal treatment regimens. Clinical prognostic factors evaluated in our series may be useful for stratification and eligibility considerations in future clinical trials.

\section{Conflict of Interests}

The authors declare that they have no conflict of interests.

\section{Authors' Contribution}

This study was designed by Metin Guclu and Canan Ersoy. Patient selection and follow-up visits were organized by Metin Guclu, Ozen Oz Gul, Soner Cander, and Oguzkaan Unal. Statistical analyses were done by Guven Ozkaya. Biochemical analyses except routine metabolic investigation such as measurements of adipocytokines were performed by Emre Sarandol. The paper was written by Metin Guclu.

\section{References}

[1] D. Devendra, E. Liu, and G. S. Eisenbarth, "Type 1 diabetes: recent developments," The British Medical Journal, vol. 328, no. 7442, pp. 750-754, 2004.

[2] S. Fourlanos, L. C. Harrison, and P. G. Colman, "The accelerator hypothesis and increasing incidence of type 1 diabetes," Current Opinion in Endocrinology, Diabetes and Obesity, vol. 15, no. 4, pp. 321-325, 2008.

[3] J. Ludvigsson, "Why diabetes incidence increases-a unifying theory," Annals of the New York Academy of Sciences, vol. 1079, pp. 374-382, 2006.

[4] D. Gordin, M. Rönnback, C. Forsblom, O. Heikkilä, M. Saraheimo, and P.-H. Groop, "Acute hyperglycaemia rapidly increases arterial stiffness in young patients with type 1 diabetes," Diabetologia, vol. 50, no. 9, pp. 1808-1814, 2007.

[5] DCCT Research Group, "The association between glycemic exposure and longterm diabetic complications in the Diabetes Control and Complications Trial," Diabetes, vol. 44, pp. 968983, 1995.

[6] J. F. Ndisang, S. Rastogi, and A. Vannacci, "Immune and inflammatory processes in obesity, insulin resistance, diabetes, and related cardiometabolic complications," Journal of Immunology Research, vol. 2014, Article ID 579560, 3 pages, 2014. 
[7] N. J. Nokoff, M. Rewers, and M. C. Green, "The interplay of autoimmunity and insulin resistance in type 1 diabetes," Discovery Medicine, vol. 13, no. 69, pp. 115-122, 2012.

[8] S. J. Cleland, B. M. Fisher, H. M. Colhoun, N. Sattar, and J. R. Petrie, "Insulin resistance in type 1 diabetes: what is 'double diabetes' and what are the risks?” Diabetologia, vol. 56, no. 7, pp. 1462-1470, 2013.

[9] S. Klaus, "Adipose tissue as a regulator of energy balance," Current Drug Targets, vol. 5, no. 3, pp. 241-250, 2004.

[10] A. Galler, G. Gelbrich, J. Kratzsch, N. Noack, T. Kapellen, and W. Kiess, "Elevated serum levels of adiponectin in children, adolescents and young adults with type 1 diabetes and the impact of age, gender, body mass index and metabolic control: a longitudinal study," European Journal of Endocrinology, vol. 157, no. 4, pp. 481-489, 2007.

[11] M. M. Barnes, D. Curran-Everett, R. F. Hamman et al., "Determinants of adiponectin levels in young people with Type 1 diabetes," Diabetic Medicine, vol. 25, no. 3, pp. 365-369, 2008.

[12] G. Fantuzzi, "Adiponectin and inflammation: consensus and controversy," Journal of Allergy and Clinical Immunology, vol. 121, no. 2, pp. 326-330, 2008.

[13] A. Vidal-Puig and S. O’Rahilly, "Resistin: a new link between obesity and insulin resistance?” Clinical Endocrinology, vol. 55, no. 4, pp. 437-438, 2001.

[14] S. S. Pang and Y. Y. Le, "Role of resistin in inflammation and inflammation-related diseases," Cellular \& Molecular Immunology, vol. 3, no. 1, pp. 29-34, 2006.

[15] J. Auwerx and B. Staels, "Leptin," The Lancet, vol. 351, no. 9104, pp. 737-742, 1998.

[16] M. Roden, C. Ludwig, P. Nowotny et al., "Relative hypoleptinemia in patients with type 1 and type 2 diabetes mellitus," International Journal of Obesity, vol. 24, no. 8, pp. 976-981, 2000.

[17] S. Del Prato, R. Nosadini, A. Tiengo et al., "Insulin-mediated glucose disposal in type I diabetes: evidence for insulin resistance," Journal of Clinical Endocrinology and Metabolism, vol. 57, no. 5, pp. 904-910, 1983.

[18] S. Mäkimattila, A. Virkamäki, R. Malmström, T. Utriainen, and H. Yki-Jarvinen, "Insulin resistance in type I diabetes mellitus: a major role for reduced glucose extraction," Journal of Clinical Endocrinology and Metabolism, vol. 81, no. 2, pp. 707-712, 1996.

[19] M. McGill, L. Molyneaux, S. M. Twigg, and D. K. Yue, "The metabolic syndrome in type 1 diabetes: does it exist and does it matter?" Journal of Diabetes and Its Complications, vol. 22, no. 1, pp. 18-23, 2008.

[20] T. J. Orchard, J. C. Olson, J. R. Erbey et al., "Insulin resistancerelated factors, but not glycemia, predict coronary artery disease in type 1 diabetes: 10-year follow-up data from the Pittsburgh epidemiology of diabetes complications study," Diabetes Care, vol. 26, no. 5, pp. 1374-1379, 2003.

[21] C. B. Patel, J. A. de Lemos, K. L. Wyne, and D. K. McGuire, "Thiazolidinediones and risk for atherosclerosis: pleiotropic effects of PPAR $\gamma$ agonism," Diabetes and Vascular Disease Research, vol. 3, no. 2, pp. 65-71, 2006.

[22] C. E. Quinn, P. K. Hamilton, C. J. Lockhart, and G. E. McVeigh, "Thiazolidinediones: effects on insulin resistance and the cardiovascular system," British Journal of Pharmacology, vol. 153, no. 4, pp. 636-645, 2008.

[23] F. Chiarelli and D. Di Marzio, "Peroxisome proliferatoractivated receptor- $\gamma$ agonists and diabetes: current evidence and future perspectives," Vascular Health and Risk Management, vol. 4, no. 2, pp. 297-304, 2008.
[24] A. Ceriello, "Thiazolidinediones as anti-inflammatory and antiatherogenic agents," Diabetes/Metabolism Research and Reviews, vol. 24, no. 1, pp. 14-26, 2008.

[25] A. A. Parulkar, M. L. Pendergrass, R. Granda-Ayala, T. R. Lee, and V. A. Fonseca, "Nonhypoglycemic effects of thiazolidinediones," Annals of Internal Medicine, vol. 134, no. 1, pp. 61-71, 2001.

[26] F. F. Samaha, P. O. Szapary, N. Iqbal et al., "Effects of rosiglitazone on lipids, adipokines, and inflammatory markers in nondiabetic patients with low high-density lipoprotein cholesterol and metabolic syndrome," Arteriosclerosis, Thrombosis, and Vascular Biology, vol. 26, no. 3, pp. 624-630, 2006.

[27] P. J. Boyle, "What are the effects of peroxisome proliferatoractivated receptor agonists on adiponectin, tumor necrosis factor-alpha, and other cytokines in insulin resistance?" Clinical Cardiology, vol. 27, no. 7, pp. 1511-1516, 2004.

[28] K. Fujisawa, T. Nishikawa, D. Kukidome et al., "TZDs reduce mitochondrial ROS production and enhance mitochondrial biogenesis," Biochemical and Biophysical Research Communications, vol. 379, no. 1, pp. 43-48, 2009.

[29] T. Nishikawa, D. Kukidome, K. Sonoda et al., "Impact of mitochondrial ROS production on diabetic vascular complications," Diabetes Research and Clinical Practice, vol. 77, supplement 1, pp. S41-S45, 2007.

[30] J. F. Ndisang, "Cross-talk between heme oxygenase and peroxisome proliferator-activated receptors in the regulation of physiological functions," Frontiers in Bioscience, vol. 19, pp. 916935, 2014.

[31] S. Tiwari and J. F. Ndisang, "The heme oxygenase system and type-1 diabetes," Current Pharmaceutical Design, vol. 20, no. 9, pp. 1328-1337, 2014.

[32] K. V. Williams, J. R. Erbey, D. Becker, S. Arslanian, and T. J. Orchard, "Can clinical factors estimate insulin resistance in type 1 diabetes?," Diabetes, vol. 49, no. 4, pp. 626-632, 2000.

[33] E. J. Epstein, J. L. Osman, H. W. Cohen, S. N. Rajpathak, O. Lewis, and J. P. Crandall, "Use of the estimated glucose disposal rate as a measure of insulin resistance in an urban multiethnic population with type 1 diabetes," Diabetes Care, vol. 36 , no. 8 , pp. 2280-2285, 2013.

[34] The Criteria Committee of the New York Heart Association, Nomenclature and Criteria for Diagnosis of Diseases of the Heart and Great Vessels, Little, Brown \& Company, Boston, Mass, USA, 9th edition, 1994.

[35] R. J. Moon, L.-A. Bascombe, and R. I. G. Holt, "The addition of metformin in type 1 diabetes improves insulin sensitivity, diabetic control, body composition and patient well-being," Diabetes, Obesity and Metabolism, vol. 9, no. 1, pp. 143-145, 2007.

[36] R. Bhat, A. Bhansali, S. Bhadada, and R. Sialy, "Effect of pioglitazone therapy in lean typel diabetes mellitus," Diabetes Research and Clinical Practice, vol. 78, no. 3, pp. 349-354, 2007.

[37] A. A. Yishak, T. Costacou, G. Virella et al., "Novel predictors of overt nephropathy in subjects with type 1 diabetes. A nested case control study from the Pittsburgh Epidemiology of Diabetes Complications cohort," Nephrology Dialysis Transplantation, vol. 21, no. 1, pp. 93-100, 2006.

[38] E. S. Kilpatrick, A. S. Rigby, and S. L. Atkin, "Insulin resistance, the metabolic syndrome, and complication risk in type 1 diabetes: 'double diabetes' in the diabetes control and complications trial," Diabetes Care, vol. 30, no. 3, pp. 707-712, 2007.

[39] S. M. Strowig and P. Raskin, "The effect of rosiglitazone on overweight subjects with type 1 diabetes," Diabetes Care, vol. 28, no. 7, pp. 1562-1567, 2005. 
[40] M. L. Stone, J. L. Walker, D. Chisholm et al., "The addition of rosiglitazone to insulin in adolescents with type 1 diabetes and poor glycaemic control: a randomized-controlled trial," Pediatric Diabetes, vol. 9, no. 4, part 1, pp. 326-334, 2008.

[41] T. Nishikawa and E. Araki, "Impact of mitochondrial ROS production in the pathogenesis of diabetes mellitus and its complications," Antioxidants and Redox Signaling, vol. 9, no. 3, pp. 343-353, 2007.

[42] M. Mishra and J. F. Ndisang, "A critical and comprehensive insight on heme oxygenase and related products including carbon monoxide, bilirubin, biliverdin and ferritin in type- 1 and type-2 diabetes," Current Pharmaceutical Design, vol. 20, no. 9, pp. 1370-1391, 2014.

[43] A. J. M. Rennings, P. Smits, M. W. Stewart, and C. J. Tack, "Fluid retention and vascular effects of rosiglitazone in obese, insulinresistant, nondiabetic subjects," Diabetes Care, vol. 29, no. 3, pp. 581-587, 2006.

[44] S. Singh, Y. K. Loke, and C. D. Furberg, "Thiazolidinediones and heart failure: a teleoanalysis," Diabetes Care, vol. 30, no. 8, pp. 2148-2154, 2007.

[45] J. Karalliedde and R. E. Buckingham, "Thiazolidinediones and their fluid-related adverse effects: facts, fiction and putative management strategies," Drug Safety, vol. 30, no. 9, pp. 741-753, 2007.

[46] S. M. St. John, J. F. Dole, and E. B. Rappaport, "Rosiglitazone does not adversely affect cardiac structure or function in patients with type 2 diabetes," Diabetes, vol. 48 , supplement 1 , p. A102, 1999.

[47] R. B. Goldberg, D. M. Kendall, M. A. Deeg et al., "A comparison of lipid and glycemic effects of pioglitazone and rosiglitazone in patients with type 2 diabetes and dyslipidemia," Diabetes Care, vol. 28, no. 7, pp. 1547-1554, 2005.

[48] H. Yki-Järvinen, "Drug therapy: thiazolidinediones," The New England Journal of Medicine, vol. 351, no. 11, pp. 1106-1118, 2004.

[49] A. C. Calkin, J. M. Forbes, C. M. Smith et al., "Rosiglitazone attenuates atherosclerosis in a model of insulin insufficiency independent of its metabolic effects," Arteriosclerosis, Thrombosis, and Vascular Biology, vol. 25, no. 9, pp. 1903-1909, 2005.

[50] D. A. Schaumberg, R. J. Glynn, A. J. Jenkins et al., "Effect of intensive glycemic control on levels of markers of inflammation in type 1 diabetes mellitus in the diabetes control and complications trial," Circulation, vol. 111, no. 19, pp. 2446-2453, 2005.

[51] R. L. Klein, S. J. Hunter, A. J. Jenkins et al., "Fibrinogen is a marker for nephropathy and peripheral vascular disease in type 1 diabetes: studies of plasma fibrinogen and fibrinogen gene polymorphism in the DCCT/EDIC cohort," Diabetes Care, vol. 26, no. 5, pp. 1439-1448, 2003.

[52] A. Verrotti, F. Basciani, G. Morgese, and F. Chiarelli, "Leptin levels in non-obese and obese children and young adults with type 1 diabetes mellitus," European Journal of Endocrinology, vol. 139, no. 1, pp. 49-53, 1998.

[53] S. T. Azar, P. A. Zalloua, M. S. Zantout, C. H. Shahine, and I. Salti, "Leptin levels in patients with type 1 diabetes receiving intensive insulin therapy compared with those in patients receiving conventional insulin therapy," Journal of Endocrinological Investigation, vol. 25, no. 8, pp. 724-726, 2002.

[54] B. Kirel, N. Doğruel, Ü. Korkmaz, F. S. Kiliç, K. Özdamar, and B. Uçar, "Serum leptin levels in type 1 diabetic and obese children: relation to insulin levels," Clinical Biochemistry, vol. 33, no. 6, pp. $475-480,2000$.
[55] C. M. Steppan, S. T. Bailey, S. Bhat et al., “The hormone resistin links obesity to diabetes," Nature, vol. 409, no. 6818, pp. 307-312, 2001.

[56] A. Shalev, N. B. Patterson, B. Hirshberg, K. I. Rother, and D. M. Harlan, "Resistin serum levels in type 1 diabetes pre- and postislet transplantation," Metabolism: Clinical and Experimental, vol. 53, no. 4, pp. 403-404, 2004.

[57] F. Celi, V. Bini, F. Papi et al., "Circulating adipocytokines in nondiabetic and Type 1 diabetic children: relationship to insulin therapy, glycaemic control and pubertal development," Diabetic Medicine, vol. 23, no. 6, pp. 660-665, 2006.

[58] J. Frystyk, L. Tarnow, T. Krarup Hansen, H.-H. Parving, and A. Flyvbjerg, "Increased serum adiponectin levels in type 1 diabetic patients with microvascular complications," Diabetologia, vol. 48, no. 9, pp. 1911-1918, 2005.

[59] D. M. Maahs, L. G. Ogden, G. L. Kinney et al., "Low plasma adiponectin levels predict progression of coronary artery calcification," Circulation, vol. 111, no. 6, pp. 747-753, 2005. 


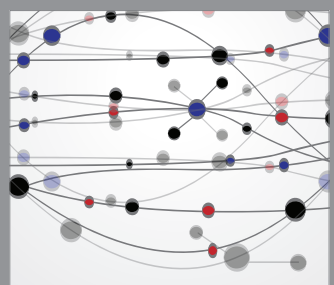

The Scientific World Journal
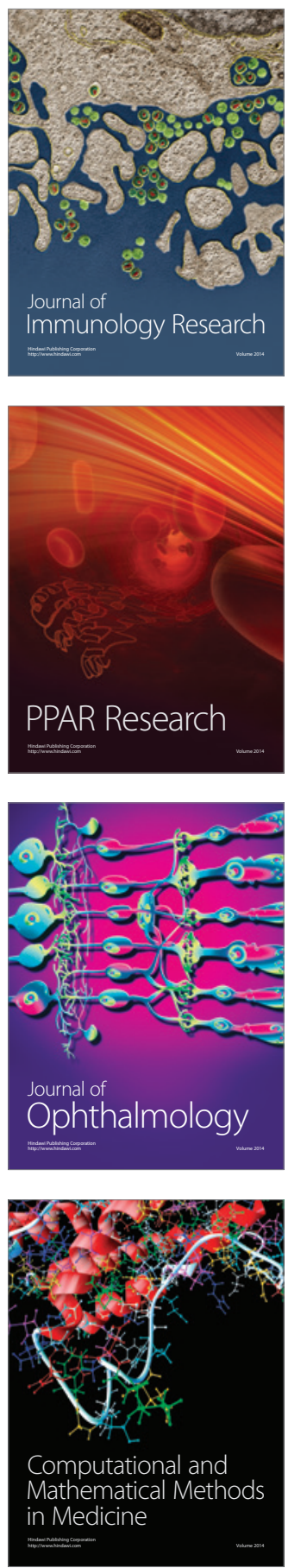

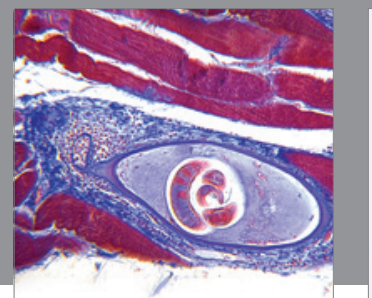

Gastroenterology

Research and Practice
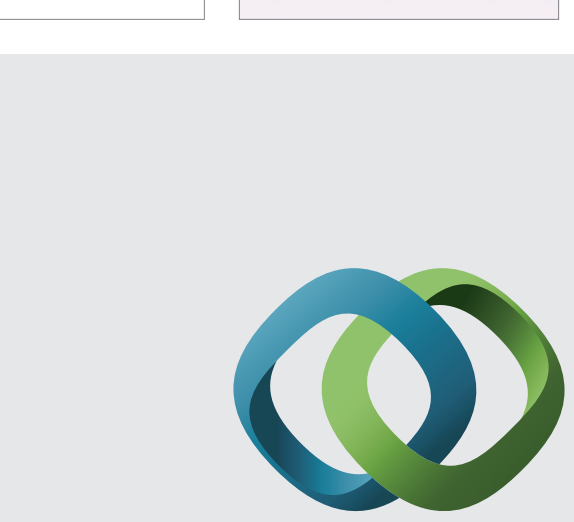

\section{Hindawi}

Submit your manuscripts at

http://www.hindawi.com
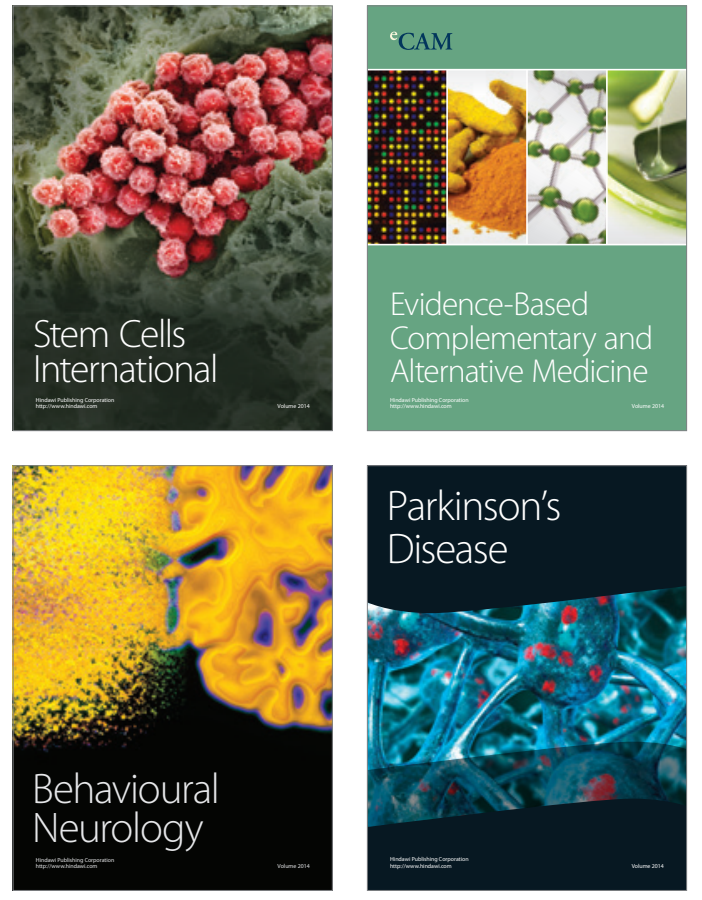


Disease Markers
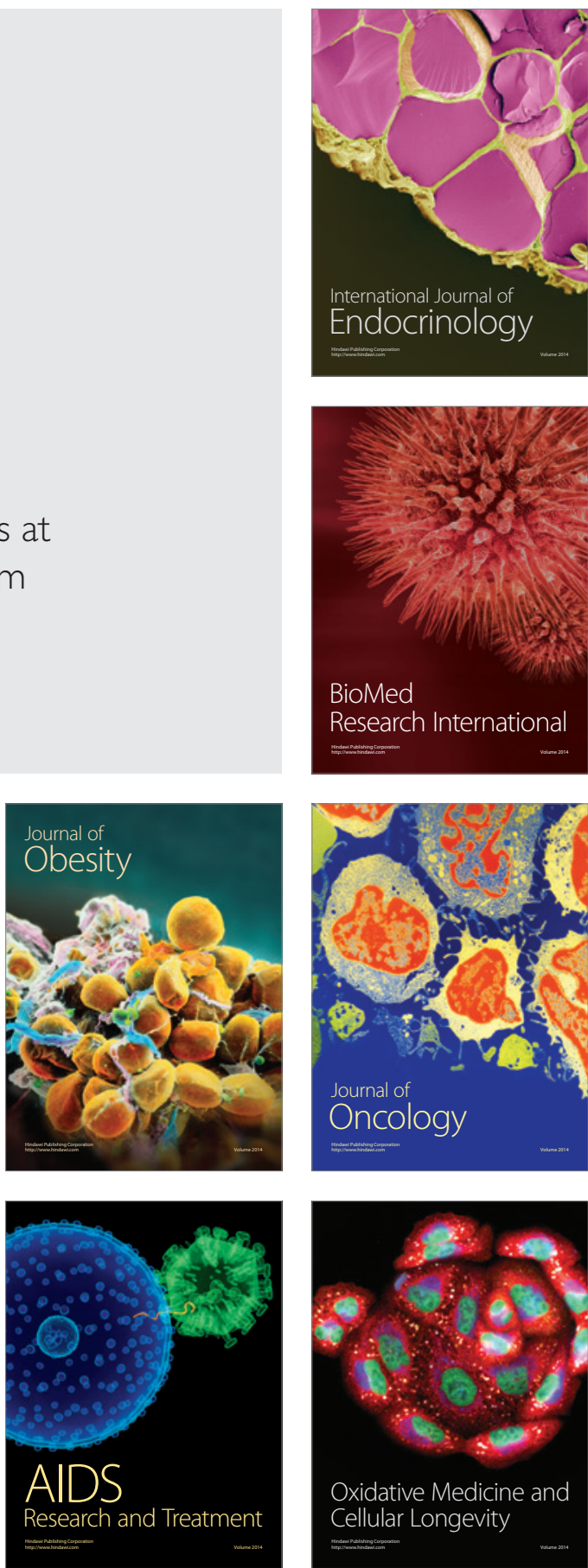